Pacific Journal of Mathematics

ON CURVATURE OF A METRIC SPACE AT A POINT 


\title{
ON CURVATURE OF A METRIC SPACE AT A POINT
}

\author{
W. A. KIRK
}

1. Introduction. In [6] Wald gives a metric definition of the curvature of a metric space $M$ at a point $p \in M$. He proves that a Gauss surface (a bounded portion of a surface of the kind studied in classical differential geometry, cf. [6, p. 33]) is characterized among all compact and convex metric spaces by the property of having curvature (in his sense) at each of its points. Recent developments in metric differential geometry include the studies of Alexandrov $[1 ; 2]$, Busemann [3], and Rinow [5] concerning spaces of bounded curvature. Rinow's concept of "region of bounded Riemann curvature" suggests another way to define the curvature of a metric space at one of its points. We introduce this definition here. Our study establishes a firm connection between the theory of Wald and the more recent work of Rinow and thereby indicates how Rinow's concept leads in a natural way to a formulation of Gaussian curvature for surfaces.

2. Definitions. For each real number $k$, positive, zero, or negative, let $S_{k}$ denote the convex two-sphere, the euclidean plane, or the hyperbolic plane of curvature $k$, respectively. A metric quadruple is said to have an imbedding curvature $k$ if it is congruent with a quadruple of $S_{k}$.

Definition. A metric space $M$ has at an accumulation point $p$ the Wald curvature $K(p)$ if (i) no neighborhood of $p$ is linear, and (ii) corresponding to each $\varepsilon>0$ there is a $\rho>0$ such that each quadruple $Q$ of points of $U(p ; \rho)$ has an imbedding curvature $k(Q)$ with $|k(Q)-K(p)|<\varepsilon$.

It has been shown [6] that a nonlinear quadruple (distinct points) has at most two imbedding curvatures, while if it contains a linear triple it has at most one. This led Wald to suggest a weakening of his original definition by restricting its application to those quadruples which contain a linear triple (see [6], p. 33). The curvature thus defined will be called the curvature $K^{\prime}(p)$. (A characterization of Gauss surfaces has recently been obtained using the curvature $K^{\prime}(p)$ [4]).

According to Rinow [5, p. 316] a region $G$ of a space $M$ with intrinsic metric is a region of Riemann curvature $\leqq k$ if:

( I ) Each two points of $G$ are joined by at least one (metric)

Received March 20, 1963. This paper is based on part of the author's University of Missouri doctoral dissertation, written under the supervision of Professor L. M. Blumenthal. 
segment of $M$ (an arc whose length is less than or equal the length of any arc joining its endpoints).

(II) Each three points of $G$ have an isometric copy in $S_{k}$.

$\left(\mathrm{III}_{\mathrm{R}}\right)$ Let $a, b, c \in G, b \neq a \neq c$, and let $S(a, b)$ and $S(a, c)$ denote segments joining $a, b$ and $a, c$, respectively. Suppose $x \in S(a, b)$ and $y \in S(a, c)$. If $A, B, C$ denotes an isometric copy of $a, b, c$ in $S_{k}$, and if $X, Y \in S_{k}$ such that $a, x, b \approx A, X, B$ and $a, y, c \approx A, Y, C$, then $x y \leqq X Y$.

Similarly, $G$ is a region of Riemann curvature $\geqq k$ if $G$ has properties I, II and $\mathrm{III}_{\mathrm{R}}^{\prime}$ where $\mathrm{III}_{\mathrm{R}}^{\prime}$ is the same as $\mathrm{III}_{\mathrm{R}}$ with $\leqq$ replaced by $\geqq$.

A connection between this and the work of Wald (i.e., the curvature $K^{\prime}(p)$ ) arises if we 'localize' the above definition as follows:

Definition. A space $M$ with intrinsic metric has at an accumulation point $p$ the curvature $R(p)$ if (i) no neighborhood of $p$ is linear, and (ii) corresponding to each $\varepsilon>0$ there is a $\rho>0$ such that $U(p ; \rho)$ is both a region of Riemann curvature $\leqq R(p)+\varepsilon$ and a region of Riemann curvature $\geqq R(p)-\varepsilon$.

Finally we state two lemmas, found in [6], that will be needed in the proofs which follow.

Lemma 1. If $p, a, b$ are non-linear points of $S_{k}$ and if $c$ is $a$. point in the interior of $\angle b p a$ such that $c p=b p$, then $a c<a b$.

Lemma 2. Let $a^{\prime}, b^{\prime}, c^{\prime}, d^{\prime}$ be a non-linear quadruple of $S_{k^{\prime}}$ with $a^{\prime} b^{\prime}+b^{\prime} c^{\prime}=a^{\prime} c^{\prime}$, and let $a^{\prime \prime}, b^{\prime \prime}, c^{\prime \prime}, d^{\prime \prime}$ be a quadruple of $S_{k^{\prime \prime}}$, where $k^{\prime}<k^{\prime \prime}$. If $a^{\prime}, b^{\prime}, c^{\prime} \approx a^{\prime \prime} b^{\prime \prime} c^{\prime \prime}$ then $a^{\prime} d^{\prime}=a^{\prime \prime} d^{\prime \prime}$ and $c^{\prime} d^{\prime}=c^{\prime \prime} d^{\prime \prime}$ imply, $b^{\prime} d^{\prime}<b^{\prime \prime} d^{\prime \prime}$.

3. A comparison of the curvatures $K^{\prime}(p)$ and $R(p)$. We now prove two theorems which illustrate the great similarity of the curvatures $K^{\prime}(p)$ and $R(p)$. Here $M$ denotes a space with intrinsic metric.

THEOREM 3.1. If the curvature $K^{\prime}(p)$ exists at $p \in M$ and if $p$ has a neighborhood in which each two points are joined by a segment of $M$, then the curvature $R(p)$ exists at $p$, and $K^{\prime}(p)=R(p)$.

Proof. Let $\varepsilon>0$, and let $U$ denote a neighborhood of $p$ whose radius $\rho$ is chosen small enough that:

(1) Each two points of $U$ are joined by a segment of $M$. 
(2) Each quadruple $Q$ of points of $U$ which contains a linear triple has an imbedding curvature $k(Q)$ where (i) $|k|<\pi^{2} /\left(16 \rho^{2}\right)$, and (ii) $k^{\prime}<k<k^{\prime \prime}$, where $k^{\prime}=K^{\prime}(p)-\varepsilon$ and $k^{\prime \prime}=K^{\prime}(p)+\varepsilon$.

(3) Each three points of $U$ are congruent with three points of $S_{k^{\prime \prime}}$.

In order to prove the theorem it need only be shown that $U$ has properties $\mathrm{III}_{R}$ and $\mathrm{III}_{\mathrm{R}}^{\prime}$ for $k^{\prime}$ and $k^{\prime \prime}$, respectively. First we show that $U$ contains all the points of any segment joining two of its points. Let $r, s \in U$. If $p, r, s$ are linear then it is clear that every point on a segment $S(r, s)$ joining $r$ and $s$ is in $U$. If $p, r, s$ are not linear, then let $t \in S(r, s)$ and suppose that $p t \geqq \rho$. This implies there exist points $y_{1}, y_{2} \in S(r, s)$ such that $y_{1} \neq y_{2}$ and $p r<p y_{1}=p y_{2}<\rho$. Since $p, y_{1}, y_{2}$ are linear, $p, r, y_{1}, y_{2} \approx p^{*}, r^{*}, y_{1}^{*}, y_{2}^{*}$ where the 'starred' points are in an $S_{k}$ with $|k|<\pi^{2} /\left(16 \rho^{2}\right)$. But then $p^{*} r^{*}<p^{*} y_{1}^{*}$, and this is not possible for $k \leqq 0$; for $k>0, p^{*} r^{*}<p^{*} y_{1}^{*}$ is only possible if the isosceles triangle whose vertices are $p^{*}, y_{1}^{*}, y_{2}^{*}$ has altitude $\geqq \pi /(2 \sqrt{k})$, which contradicts $(2)$. Hence $p t<\rho$ and $t \in U$.

Now let $a, b, c$ be points of $U$ with $b \neq a \neq c$, and let $x \in S(a, b)$ and $y \in S(a, c)$, where $S(a, b)$ and $S(a, c)$ denote segments joining $a, b$ and $a, c$, respectively. Since $U$ contains all the points of a segment joining any two of its points, $x$ and $y$ are in $U$. Hence by (2), $a, x, b, c$ and $a, x, y, c$ have imbedding curvatures $k_{1} \geqq k^{\prime}$ and $k_{2} \geqq k^{\prime}$, respectively. Also, since $k^{\prime}<k^{\prime \prime}$, it follows from (3) that $a, b, c$ has an isometric copy $A^{\prime}, B^{\prime}, C^{\prime}$ in $S_{k^{\prime}}$. Thus, if $X^{\prime}$ and $Y^{\prime}$ are points of $S_{k^{\prime}}$ such that $a, x, b \approx A^{\prime}, X^{\prime}, B^{\prime}$ and $a, y, b \approx A^{\prime}, Y^{\prime}, B^{\prime}$ we have, by Lemma $2, X^{\prime} C^{\prime} \leqq x c$. Let $X^{*}$ denote a point of $S_{k^{\prime}}$ such that $X^{*} C^{\prime}=x c$ and $X^{*} A^{\prime}=x a$. It follows from Lemma 1 that $\angle X^{*} A^{\prime} C^{\prime} \geqq$ $\angle X^{\prime} A^{\prime} C^{\prime}$ and hence $X^{*} Y^{\prime} \geqq X^{\prime} Y^{\prime}$. But by Lemma $2, X^{*} Y^{\prime} \leqq x y$ since $a, x, y, c$ has imbedding curvature $k_{2} \geqq k^{\prime}$. Therefore $X^{\prime} Y^{\prime} \leqq x y$ and $\mathrm{III}_{\mathrm{R}}$ is satisfied. In the same way it can be shown that $\mathrm{III}_{\mathrm{R}}^{\prime}$ is satisfied in $U$ for $k^{\prime \prime}$.

THEOREM 3.2. If the curvature $R(p)$ exists at $p \in M$, the curvature $K^{\prime}(p)$ does also, and $K^{\prime}(p)=R(p)$.

Proof. Let $\varepsilon>0$ and let $U(p ; \rho)$ be a region of Riemann curvature $\leqq R(p)+\varepsilon$ and $\geqq R(P)-\varepsilon$. Put $k^{\prime}=R(p)-\varepsilon$ and $k^{\prime \prime}=R(p)+\varepsilon$ (choosing $\rho<\pi /\left(4 \sqrt{k^{\prime \prime}}\right)$ if $\left.k^{\prime \prime}>0\right)$. If $Q=\left(p_{1}, p_{2}, p_{3}, p_{4}\right)$ denotes an arbitrary quadruple of $U(p ; \rho)$ for which $p_{1} p_{2}+p_{2} p_{3}=p_{1} p_{3}$, and if $\left(p_{1}^{\prime}, p_{2}^{\prime}, p_{3}^{\prime}, p_{4}^{\prime}\right)$ and $\left(p_{1}^{\prime \prime}, p_{2}^{\prime \prime}, p_{3}^{\prime \prime}, p_{4}^{\prime \prime}\right)$ denote quadruples of $S_{k^{\prime}}$ and $S_{k^{\prime \prime}}$, respectively, such that $p_{i} p_{j}=p_{i}^{\prime} p_{j}^{\prime}=p_{i}^{\prime \prime} p_{j}^{\prime \prime}$ for all index pairs $(i, j)$ except $(2,4)$, then by $\operatorname{III}_{\mathrm{R}} p_{2} p_{4} \geqq p_{2}^{\prime} p_{4}^{\prime}$, while by $\operatorname{III}_{R}^{\prime} p_{2} p_{4} \leqq p_{2}^{\prime \prime} p_{4}^{\prime \prime}$. It 
follows that there is a number $k$ between $k^{\prime}$ and $k^{\prime \prime}$ for which $Q$ has imbedding curvature $k$. Since both $k^{\prime}$ and $k^{\prime \prime}$ have limit $R(p)$ as $\varepsilon \rightarrow 0$, $M$ has curvature $K^{\prime}(p)$ at $p$ where $K^{\prime}(p)=R(p)$.

4. Remarks. Wald proved that if $M$ is a Gauss surface then the curvature $K(p)$ is the Gauss curvature of $M$ at $p[6, \mathrm{p} .42]$. It is clear that for $p \in M, K(p)=K^{\prime}(p)$, and by Theorem 3.1, $K^{\prime}(p)=$ $R(p)$. Hence the curvature $R(p)$ is the Gauss curvature of $M$ at $p$.

There is a distinction between the curvature $K^{\prime}(p)$ (or $R(p)$ ) and the Wald curvature $K(p)$. Wald proved that the existence of the curvature $K(p)$ at each point of a compact and convex metric space implies that the space is two-dimensional [6, p. 31]. The curvature $K^{\prime}(p)$ may exist in spaces of arbitrary dimension (e.g. spaces of constant Riemannian curvature). While it is the Gauss curvature for surfaces the significance of its existence in spaces of higher dimension is not known.

\section{REFERENCES}

1. A. D. Alexandrov, Die innere Geometrie der konvexen Flächen, Akademie-Verlag, Berlin, 1955.

2. — Über eine Verallgemeinerung der Riemannschen Geometrie. Bericht von der Riemmann-Tagung des Forschungsinstituts für Mathematik: Der Begriff des Raumes in der Geometrie. Schriftenreihe des Forschungsinstituts für Math. H. 1, AkademieVerlag, Berlin 1957, 33-84.

3. H. Busemann, The Geometry of Geodesics, Academic Press, New York, 1955.

4. W. A. Kirk, A Metrization of Gauss Curvature of Surfaces, Thesis, University of Missouri, 1962.

5. W. Rinow, Die innere Geometrie der metrischen Räume, Springer-Verlag, Berlin, 1961.

6. A. Wald, Begründung einer koordinatenlosen Differentialgeometrie der Flächen, Ergebnisse eines mathematischen Kolloquiums H., 7 (1935), 24-46.

UNIVERsity of California, Riverside 


\section{PACIFIC JOURNAL OF MATHEMATICS}

\section{EDITORS}

Robert Osserman

Stanford University

Stanford, California

M. G. Arsove

University of Washington

Seattle 5 , Washington
J. DugundjI

University of Southern Califorma: Los Angeles 7, California

Lowell J. Paige

University of California

Los Angeles 24, California

\section{ASSOCIATE EDITORS}

E. F. BECKENBACH

B. H. NeumanN

F. WOLF

K. YosIDA

\section{SUPPORTING INSTITUTIONS}

UNIVERSITY OF BRITISH COLUMBIA

CALIFORNIA INSTITUTE OF TECHNOLOGY

UNIVERSITY OF CALIFORNIA

MONTANA STATE UNIVERSITY

UNIVERSITY OF NEVADA

NEW MEXICO STATE UNIVERSITY

OREGON STATE UNIVERSITY

UNIVERSITY OF OREGON

OSAKA UNIVERSITY

UNIVERSITY OF SOUTHERN CALIFORNIA
STANFORD UNIVERSITY

UNIVERSITY OF TOKYO

UNIVERSITY OF UTAH

WASHINGTON STATE UNIVERSITY

UNIVERSITY OF WASHINGTON

AMERICAN MATHEMATICAL SOCIETY CALIFORNIA RESEARCH CORPORATION SPACE TECHNOLOGY LABORATORIES NAVAL ORDNANCE TEST STATION 


\section{Pacific Journal of Mathematics}

\section{Vol. 14, No. 1 \\ May, 1964}

Richard Arens, Normal form for a Pfaffian .........................

Charles Vernon Coffman, Non-linear differential equations on cones in Banach

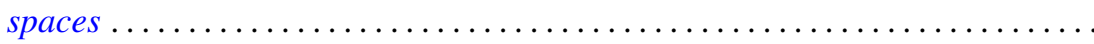

Ralph DeMarr, Order convergence in linear topological spaces ..............

Peter Larkin Duren, On the spectrum of a Toeplitz operator ................

Robert E. Edwards, Endomorphisms of function-spaces which leave stable all

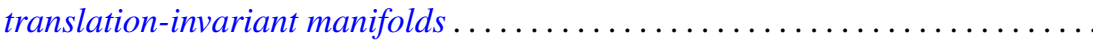

Erik Maurice Ellentuck, Infinite products of isols . . . . . . . . . . . . . . . . 49

William James Firey, Some applications of means of convex bodies . . . . . . . . 53

Haim Gaifman, Concerning measures on Boolean algebras ............. 61

Richard Carl Gilbert, Extremal spectral functions of a symmetric operator. . . . . . 75

Ronald Lewis Graham, On finite sums of reciprocals of distinct nth powers ..... 85

Hwa Suk Hahn, On the relative growth of differences of partition functions ...... 93

Isidore Isaac Hirschman, Jr., Extreme eigen values of Toeplitz forms associated

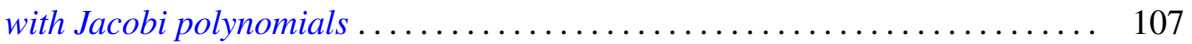

Chen-jung Hsu, Remarks on certain almost product spaces . . . . . . . . . . . 163

George Seth Innis, Jr., Some reproducing kernels for the unit disk . . . . . . . . . 177

Ronald Jacobowitz, Multiplicativity of the local Hilbert symbol . . . . . . . . . . . 187

Paul Joseph Kelly, On some mappings related to graphs ................. 191

William A. Kirk, On curvature of a metric space at a point . . . . . . . . . . . . 195

G. J. Kurowski, On the convergence of semi-discrete analytic functions . . . . . . . 199

Richard George Laatsch, Extensions of subadditive functions . . . . . . . . . . . 209

V. Marić, On some properties of solutions of $\Delta \psi+A\left(r^{2}\right) X \nabla \psi+C\left(r^{2}\right) \psi=0 \ldots 217$

William H. Mills, Polynomials with minimal value sets . . . . . . . . . . . 225

George James Minty, Jr., On the monotonicity of the gradient of a convex

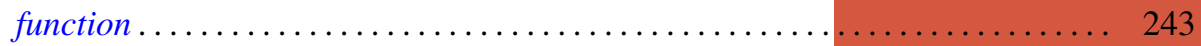

George James Minty, Jr., On the solvability of nonlinear functional equations of 'monotonic' type ................................... 249

J. B. Muskat, On the solvability of $x^{e} \equiv e(\bmod p) \ldots \ldots \ldots \ldots \ldots \ldots \ldots \ldots . \ldots \ldots$

Zeev Nehari, On an inequality of $P . R$. Bessack ................... 261

Raymond Moos Redheffer and Ernst Gabor Straus, Degenerate elliptic

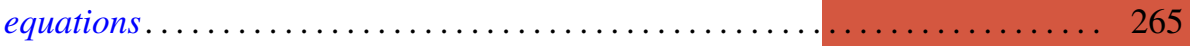

Abraham Robinson, On generalized limits and linear functionals . . . . . . . . . 269

Bernard W. Roos, On a class of singular second order differential equations with a

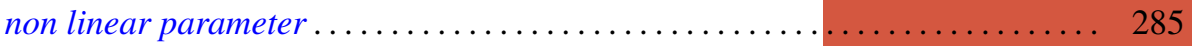

Tôru Saitô, Ordered completely regular semigroups . . . . . . . . . . . . . . . . 295

Edward Silverman, A problem of least area ....................... 309

Robert C. Sine, Spectral decomposition of a class of operators . . . . . . . . . 333

Jonathan Dean Swift, Chains and graphs of Ostrom planes . . . . . . . . . . . 353

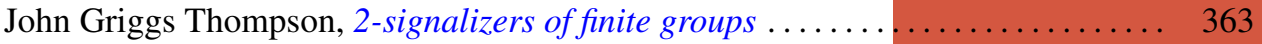

Harold Widom, On the spectrum of a Toeplitz operator . . . . . . . . . . . . . 365 